\title{
Políticas públicas de ATER e agroecologia: uma análise comparada no estado de Pernambuco
}

\section{Public policy ATER and agroecology: a comparative analysis in the Pernambuco}

Filipe Augusto Xavier Lima

filipeaxlima@hotmail.com

Doutor em Extensão Rural, professor da Universidade Federal do Ceará (UFC) 


\title{
RESUMO
}

Este artigo busca descrever as ações de extensão rural voltadas à agricultura sustentável, realizadas por instituições que apoiam os agricultores de base agroecológica. Para isso, apresentase uma abordagem comparativa envolvendo dois grupos de agricultores familiares de Pernambuco, um ligado a uma associação agroecológica, e outro, formado por assentados de um programa oficial de reforma agrária. Para o levantamento de dados foram realizadas entrevistas com as fontes-chave e com agricultores participantes das duas experiências. A pesquisa demonstra que, paralelamente às políticas preconizadas pela esfera governamental nos últimos anos e ao estímulo à incorporação da Agroecologia às dinâmicas de desenvolvimento rural, é fundamental o apoio de outros atores para a superação das limitações em torno das diferentes situações socioeconômicas, produtivas, ambientais e de organização associativa presentes nas estratégias e experiências dos agricultores familiares.

Palavras-chave: Agricultura Familiar; Agricultura Sustentável; Assentamentos; Desenvolvimento Rural Sustentável; Extensão Rural.

\begin{abstract}
This article seeks to describe the extension of actions aimed at sustainable agriculture, carried out by institutions that support farmers in agroecological base. For this, we present a comparative approach involving two groups of farmers of Pernambuco, one connected to an agroecological association, and another formed by setting an official program of agrarian reform. For the survey data, interviews with key sources and with participating farmers of the two experiments were performed. Research shows that, alongside the policies advocated by the governmental sphere in recent years and encouraging the incorporation of Agroecology rural development dynamics, it is essential the support of other actors to overcome the limitations around the different socioeconomic situations, productive, environmental and membership organization present in the strategies and experiences of family farmers.
\end{abstract}

Keywords: Family Farmer; Sustainable Agriculture; Sustainable Rural Development; Settlements; Rural Extension. 


\section{Introdução}

A Política Nacional de Assistência Técnica e Extensão Rural (PNATER) de 2004, que se alicerçou na relação entre Agricultura familiar, Agroecologia e Desenvolvimento rural sustentável, direcionou os serviços de Assistência técnica e Extensão rural (Ater) em uma perspectiva de apoio às comunidades rurais para a elaboração de novas estratégias de desenvolvimento rural, particularizando as unidades de produção da agricultura familiar.

Os pressupostos da Agroecologia foram incorporados à PNATER em decorrência de uma reflexão aprofundada sobre os impactos socioambientais e econômicos causados pelos modelos de desenvolvimento rural historicamente implementados no Brasil (CAPORAL; COSTABEBER, 2007). Na tentativa de responder ao desafio de oferecer uma extensão rural pública e de qualidade, que englobasse, além das demandas produtivas, as demandas ambientais e sociais para as populações rurais, o Ministério do Desenvolvimento Agrário (MDA) destacou como objetivo geral da PNATER de 2004 o estímulo e apoio a iniciativas de desenvolvimento rural sustentável, envolvendo atividades agrícolas e não agrícolas, tendo como meta o fortalecimento da agricultura familiar e incorporando os princípios da Agroecologia como eixo orientador das ações (BRASIL, 2004, p. 9).

No início de 2010, o país passou a contar com a primeira Lei de Ater, de nº 12.188, de 11 de janeiro de 2010, que seria a forma de estruturar legalmente os serviços de Ater. Entretanto, paradoxalmente, a referida lei rompe com a preocupação central da PNATER de 2004, ao desconsiderar os aspectos relacionados à Agroecologia presentes na política. Isso porque, embora os objetivos e princípios dos dois documentos se apresentem de forma semelhante em alguns pontos, nota-se que, diferentemente do que ocorre com a PNATER de 2004, a lei de 2010 não faz referência nenhuma aos princípios da Agroecologia como eixo orientador de suas ações, optando, apenas, em utilizar a expressão "agricultura de base ecológica", como está presente em um dos seus artigos, para o enfoque preferencial ao desenvolvimento de sistemas de produção sustentáveis.

Para Caporal (2011), o que ocorreu, diante dos aspectos da lei de 2010, caracteriza-se ou como retrocesso com respeito ao que vinha acontecendo a partir da PNATER de 2004, isto é, a possibilidade de promover o desenvolvimento rural sustentável e o apoio a processos de transição agroecológica para o estabelecimento de estilos de agriculturas sustentáveis, baseadas nos princípios da Agroecologia; ou como 
futuro problema para a ação extensionista e para suas entidades. $\mathrm{O}$ autor justifica que, na elaboração da Lei $\mathrm{n}^{0} 12.188$, os gestores menosprezaram a participação dos setores interessados e houve a exclusão da Agroecologia na política pública de extensão rural.

No ano de 2012, foi realizada a $1^{\text {a }}$ Conferência Nacional sobre Assistência Técnica e Extensão Rural (CNATER), com a temática Ater para a agricultura familiar e reforma agrária e o desenvolvimento sustentável do Brasil rural. A $1^{\mathrm{a}}$ CNATER teve por finalidade propor diretrizes, prioridades e estratégias para o Programa Nacional de Assistência Técnica e Extensão Rural (PRONATER), tendo como referência a PNATER e em atendimento à Lei $\mathrm{n}^{\mathrm{o}} 12.188$ e suas regulamentações. O que é importante destacar, no documento da $1^{\text {a }}$ CNATER, é que a Agroecologia é reincorporada ao discurso governamental, fazendo-se presente, inclusive, nas proposições relacionadas aos cinco eixos temáticos do documento: Ater e Desenvolvimento rural sustentável; Ater para a diversidade da agricultura familiar e a redução das desigualdades; Ater e Políticas públicas; Gestão, financiamento, demanda e oferta dos serviços de Ater; e Metodologias de Ater - abordagens de Extensão rural.

Também em 2012, por meio do Decreto $\mathrm{n}^{\circ}$ 7.794, de 20 de agosto de 2012, foi instituída a Política Nacional de Agroecologia e Produção Orgânica (PNAPO), “com o objetivo de integrar, articular e adequar políticas, programas e ações indutoras da transição agroecológica e da produção orgânica e de base agroecológica [...]" (BRASIL, 2012, p. 1). Frente a isso, parece haver uma preocupação da política em delimitar, por meio de diretrizes, instrumentos, conteúdos e competências, as características relacionadas à Agroecologia e as diferentes manifestações de agricultura sustentável. Na sequência, para execução e operacionalização da PNAPO, cria-se o Plano Nacional de Agroecologia e Produção Orgânica (PLANAPO), que também se caracteriza como uma política pública do Governo Federal para ampliar e efetivar ações para o desenvolvimento rural sustentável.

Mais recentemente, o debate se voltou para a criação da Agência Nacional de Assistência Técnica e Extensão Rural (ANATER), onde o cerne da discussão esteve nos possíveis desdobramentos da institucionalização de uma agência nacional para coordenar a Ater e a pesquisa, aumentando o número de agricultores que acessam tecnologias no campo e credenciando entidades que executarão os serviços de Ater. Apesar dos entraves evidenciados com a criação da ANATER, como, por exemplo, uma melhor definição de quem será o público-alvo beneficiado por seus serviços, a agência destaca, entre a sua 
atuação prioritária para as primeiras chamadas, propostas para a Agroecologia e produção orgânica.

Desse modo, essa breve retrospectiva acerca das recentes políticas públicas de Ater fez com que emergisse as seguintes questões norteadoras deste estudo: que ações de extensão rural vêm sendo realizadas por instituições que apoiam os agricultores de base agroecológica? E de que forma as políticas públicas de Ater influenciam as experiências de desenvolvimento rural? Parte-se dessas questões como ponto de partida porque, desde a criação da PNATER em 2004, observa-se que as políticas de extensão rural subsequentes apresentam ambiguidades, distorções e fragilidades, tanto de ordem teórica quanto metodológica, no que se refere às abordagens sobre a Agroecologia e às estratégias de desenvolvimento rural sustentável, fato que pode causar prejuízos e incertezas para as ações dos extensionistas e junto aos agricultores familiares, público priorizado pelas políticas de Ater.

Por esse motivo, neste artigo, realiza-se um estudo comparativo a partir de dois municípios do estado de Pernambuco: Santa Cruz da Baixa Verde, na mesorregião do Sertão, e São Lourenço da Mata, localizado na Região Metropolitana de Recife (RMR). Voltados anteriormente para a agricultura pautada no monocultivo da cana-de-açúcar, ambos os municípios concentram, atualmente, processos de transição agroecológica, os quais se desenvolveram, no primeiro caso, ainda na década de 1990 e, no segundo caso, no final dos anos 2000 .

Em Santa Cruz da Baixa Verde, para fazer frente aos manejos tradicionais associados à cana-de-açúcar, alguns agricultores participaram de um processo de transição agroecológica que contou, inicialmente, com o apoio do Sindicato dos Trabalhadores Rurais de Triunfo (município vizinho de Santa Cruz da Baixa Verde), do Serviço Alemão de Cooperação Técnica e Social (Deutscher Entwicklungsdienst - DED) e do Centro de Desenvolvimento Agroecológico Sabiá, durante a década de 1990. Os agricultores tinham, entre seus objetivos: desenvolver atividades agrícolas que gerassem renda e preservassem o meio ambiente, promover a organização associativa dos agricultores, trabalhar o processo de beneficiamento e comercialização da produção e incentivar a integração de jovens e mulheres ao trabalho. Dentro do processo de transição, foi fundada, no ano de 1996, a Associação de Desenvolvimento Rural Sustentável da Serra da Baixa Verde (ADESSU). 
Na realidade do assentamento, em 2009, o Núcleo de Agroecologia e Campesinato (NAC), vinculado ao Departamento de Educação da Universidade Federal Rural de Pernambuco (UFRPE), iniciou um projeto de pesquisa financiado pelo Conselho Nacional de Desenvolvimento Científico e Tecnológico (CNPq), com o intuito de auxiliar o processo de transição no assentamento por meio de diagnósticos participativos, reuniões, capacitações, intercâmbios, unidades de experimentação agroecológica (UEAs) etc.

Com a discussão tecida a seguir, procurou-se, principalmente, descrever as ações de extensão rural voltadas à agricultura sustentável, realizadas por instituições que apoiam os agricultores de base agroecológica da ADESSU e do assentamento Chico Mendes III.

\section{Metodologia}

Possivelmente, este trabalho inclui elementos de mais de um tipo de estudo. Isso porque a pesquisa se inicia como exploratória, buscando examinar um tema ou problema de pesquisa pouco estudado e do qual se tem muitas dúvidas. A pesquisa passa a ser descritiva no momento em que busca descrever situações, acontecimentos e feitos. Termina como estudo explicativo, porque vai além da descrição de conceitos ou fenômenos, quer dizer, tenta responder às causas dos acontecimentos e compreender por que ocorre um fenômeno e em quais condições.

Para o levantamento de dados, primeiramente optou-se por entrevistas direcionadas as fontes-chave de informação, que, segundo Rojas Soriano (2004), são aqueles informantes que possuem experiências e conhecimentos relevantes sobre o tema em estudo ou que estão, na sua comunidade ou no seu grupo social, em posição (econômica, social ou cultural) de fornecer dados que outras pessoas desconhecem total ou parcialmente. Dito isso, na experiência da ADESSU foram entrevistados três fonteschave (um extensionista do Instituto Agronômico de Pernambuco (IPA), um expresidente da associação e um jovem "difusor em Agroecologia"). Do lado do assentamento, foram ouvidos quatro fontes-chave (um técnico-administrativo e três estagiários da UFRPE ligados aos projetos do NAC).

$\mathrm{Na}$ sequência, as entrevistas com base em um roteiro estruturado se estenderam para seis agricultoras associadas à ADESSU e para sete representantes (três homens e quatro mulheres) de cada família assentada no Chico Mendes III. As entrevistas foram 
realizadas de forma individualizada, tal como preconiza essa técnica de investigação. Os agricultores familiares ligados à ADESSU e ao Assentamento Chico Mendes III foram escolhidos com o apoio das fontes-chave dos casos em questão. Para a transformação dos discursos dos entrevistados em textos formais, e com o objetivo de manter o anonimato de cada informante, foram utilizadas siglas seguidas de um número. Então, as agricultoras da ADESSU foram denominadas de AAD, as fontes-chave ligadas à ADESSU foram denominadas de FCAD, os agricultores assentados do Chico Mendes III foram denominados de ACM e as fontes-chave ligadas ao assentamento, de FCCM.

\section{Resultados e discussão: Apoio de atores locais e a formação de técnicos para prestação de assistência aos associados da ADESSU}

A respeito da transição agroecológica, Caporal e Costabeber (2007) afirmam que ela pode ser definida como um processo gradual de mudança, que ocorre ao longo do tempo, nas formas de manejo e gestão dos agroecossistemas, tendo como objetivo a passagem de um sistema de produção convencional a outro sistema de produção que incorpore princípios, métodos e tecnologias de base ecológica. Para Costabeber (1998, p. 39), a transição agroecológica também pode ser definida como "a passagem do modelo produtivista convencional a formas de produção mais evolucionadas desde o ponto de vista da conservação dos recursos naturais e, consequentemente, mais sustentáveis no médio e longo prazos". Ainda de acordo com Costabeber (1998), a característica principal desse processo de mudança seria a "ecologização" da agricultura, que passa a assumir considerações de caráter ambiental e biofísico, além de um papel ativo na determinação das práticas agrícolas.

Em Santa Cruz da Baixa Verde, os agricultores familiares da ADESSU, no início do seu processo de transição agroecológica, realizavam práticas agrícolas mais tradicionais, especialmente visando à recuperação do solo, com curvas de nível e muretas de pedras em suas áreas produtivas. Em um segundo momento, veio a implantação dos Sistemas Agroflorestais (SAFs) nas propriedades dos agricultores envolvidos na experiência, seguida de um longo trabalho de conscientização sobre a importância da diversificação das culturas.

De acordo com a fonte-chave FCAD1, os responsáveis por essas iniciativas foram os chamados "difusores em Agroecologia", que, antigamente, eram os associados mais experientes, que faziam o acompanhamento junto aos demais sócios. $\mathrm{O}$ entrevistado 
destaca essa socialização dos conhecimentos agroecológicos como o ponto-chave de todo o processo, lembrando, ainda, que os 12 agricultores que participaram da criação da ADESSU prestavam assessoria uns aos outros, em forma de mutirão. O grupo contou, também, com a contribuição de um técnico do Centro Sabiá, que auxiliou na parte da formação dos "difusores" e com algumas assessorias esporádicas diretamente nas propriedades.

$\mathrm{Na}$ medida em que as parcerias entre os atores locais foram sendo consolidadas, novas iniciativas emergiram na experiência, como a construção de cisternas de placas e de caldeirões de pedra, além da distribuição de mudas de palma forrageira para os associados, no intuito de levar às transformações preconizadas pelos projetos pioneiros (FCAD2). Uma agricultora entrevistada revelou que, para entrar na ADESU, foi necessário participar de três reuniões com todos os associados e receber a visita dos "difusores" em sua horta, para que eles conhecessem a sua produção de base agroecológica. A partir disso, a visita dos "difusores" passou a ocorrer mensalmente, com foco no controle de "pragas" em seu plantio (AAD1). Outras agricultoras ouvidas citam, além dos encontros mensais que ocorreram com os "difusores" da ADESSU, as práticas oferecidas em suas unidades de produção agropecuária (UPAs), nas quais prevaleceram a adubação verde para melhorar as condições do solo, a cobertura morta para a conservação da umidade, as valetas para irrigação e as curvas de nível.

Nos dias atuais, o entrevistado FCAD1 comenta que existe outra dinâmica em relação aos serviços de Ater, baseada na PNATER de 2004 e na Agroecologia, com um maior nível de organização, buscando sempre cumprir o calendário das visitas agendadas junto aos associados e as atividades formativas programadas. Caporal (2009) define esse tipo de extensão rural agroecológica como sendo:

Um processo de intervenção de caráter educativo e transformador, baseado em metodologias de investigação-ação-participante, que permita o desenvolvimento de uma prática social mediante a qual os sujeitos do processo buscam a construção e sistematização de conhecimentos que os levem a incidir conscientemente sobre a realidade, com o objetivo de alcançar um modelo de desenvolvimento socialmente equitativo e ambientalmente sustentável, adotando os princípios teóricos da Agroecologia como critério para o desenvolvimento e seleção das soluções mais adequadas e compatíveis com as condições específicas de cada agroecossistema e do sistema cultural das pessoas implicadas em seu manejo (CAPORAL, 2009, p. 12). 
Esse trabalho envolve a participação tanto dos técnicos de outras instituições como a dos "difusores" da ADESSU (hoje em dia, são jovens filhos de agricultores familiares, geralmente ligados à associação), e a assessoria individual continua acontecendo mensalmente, contemplando todos os associados. As atividades formativas, por sua vez, são feitas em grupo, a cada dois meses.

A única instituição que não consegue incluir todos os associados em seus serviços de Ater prestados, segundo as fontes-chave, é o IPA. Isso porque, como situa o informante FCAD3, "nem todos os sócios da ADESSU podem ser legitimados enquanto agricultores familiares, para a emissão da sua Declaração de Aptidão ao Pronaf (DAP)". Somente a partir dessa resolução burocrática é que o IPA presta assessoria junto aos agricultores familiares. Para aqueles que já possuem a DAP e são reconhecidos como agricultores familiares na esfera governamental, o fonte-chave explica como é a assistência do IPA:

Para esses agricultores, vêm as orientações na questão da produção, principalmente direcionada à produção da rapadura e ao acesso a algumas políticas públicas mesmo, como o Garantia-Safra, o Pronaf e alguns projetos daqui do governo do Estado, que seria a distribuição de sementes de milho e feijão, questão do preparo do solo e o incentivo à própria organização [...]. Diante da demanda, tem a inclusão dentro das tarefas que a gente desenvolve aqui no município. Desde a questão da emissão de uma DAP, até o acesso ao crédito e outras ações, a gente está acompanhando. Agora isso vai muito da demanda da própria associação (FCAD3).

Para o entrevistado FCAD2, a falta da oferta de serviços de Ater é suprida pelo trabalho dos funcionários da própria ADESSU, que atualmente conta com sete "difusores" em seu quadro permanente, prestando assistência técnica mensal às famílias envolvidas no processo de transição agroecológica e nos outros projetos subsequentes, que abrange um universo de mais de 200 famílias da região. Na equipe, estão "difusores em Agroecologia", técnicos mobilizadores de campo e dois técnicos cedidos pelo Centro Sabiá. Esses últimos, conforme ressalta a associada AAD4, estão no primeiro ano de experiência com o grupo de Ater da ADESSU, conhecendo aos poucos a localidade e introduzidos paulatinamente no trabalho de campo, o que não permitiu, até o momento, a visita a todas as propriedades dos associados.

Quando se fala nos serviços de Ater em Santa Cruz da Baixa Verde, o fonte-chave FCAD1 assinala que toda a discussão é feita a partir das práticas agroecológicas, sobretudo aquelas voltadas ao beneficiamento, ao processo formativo ou que envolvam 
outras questões técnicas na produção. Ele recorda que, no âmbito do sistema agroflorestal, por exemplo, são comuns o manejo de podas e o controle de "pragas" com defensivos naturais. Outro ponto a considerar é que, frequentemente, os “difusores" responsáveis pelo acompanhamento dos associados participam de cursos sobre Agroecologia, para conhecer e estudar novas práticas e estar socializando as informações adquiridas com o grupo maior (FCAD2).

No campo dos fatores limitantes para os serviços de Ater, o entrevistado FCAD2 aponta que, mesmo com os "difusores" buscando atualizar-se sobre as práticas agroecológicas mais adequadas para cada tipo de situação específica, ainda é difícil encontrar materiais técnicos direcionados para a Agroecologia, quando comparados com a gama de estudos voltados para a agricultura convencional. Outro entrevistado utiliza-se da seguinte argumentação para falar das dificuldades nos serviços de Ater:

A questão da Agroecologia ainda é um tema polêmico, tanto pela formação dos técnicos como dos agricultores. O que ainda se falta trabalhar é a própria abordagem dessas políticas com o quadro técnico, para que possa direcionar essas atividades, baseada nessas questões. Às vezes o técnico até termina executando, mas ele não tem ciência o que é a orientação dessas políticas, não enxerga o vínculo com a política. Então, a gente está da mesma forma, sem essa preocupação. Só se fortaleceu institucionalmente e por estar se cobrando algumas ações diretas para isso (FCAD3).

Apesar das limitações, de maneira geral, os agricultores da ADESSU afirmam terem sido atendidos quando procuraram os serviços de Ater por algum tipo de problema em suas UPAs, seja na parte vegetal, seja animal. Quanto à influência das políticas públicas no processo de transição agroecológica, o informante FCAD3 esclarece que, a partir do momento em que o associado pode se declarar como verdadeiro agricultor familiar, isto é, enquadrar-se nos critérios da Lei $\mathrm{n}^{\circ}$ 11.326, de 24 de julho de 2006, que estabelece as diretrizes para a formulação da Política Nacional da Agricultura Familiar e Empreendimentos Familiares Rurais, ele vai poder acessar alguns programas governamentais específicos, o que favorece cada experiência particular.

De fato, ser reconhecido como agricultor familiar se torna uma vantagem para os sócios da ADESSU, especialmente pela possibilidade de acesso ao crédito rural que essa condição permite, visando ao investimento em suas propriedades. Somando, merece destaque a inserção dos associados em programas governamentais como o Programa 
Nacional de Alimentação Escolar (PNAE) e o Programa de Aquisição de Alimentos (PAA), pelos quais os agricultores familiares comercializam o excedente e contribuem para a segurança alimentar da própria comunidade. Efetivamente, é o PAA que se sobressai na experiência, porque ele abrange toda a cadeia produtiva, desde a produção até a comercialização, tornando-se o diferencial para as famílias agricultoras, pela melhoria na renda que esse programa vem proporcionando. Nesse sentido, com a organização, participação e acesso às políticas públicas, os agricultores passaram a ter mais acesso a informações antes não alcançadas e, com esse conhecimento, tornou-se mais fácil estreitar os laços com os serviços de Ater governamental.

Outro elemento importante, destacado pelo entrevistado FCAD3, é que, após a PNATER de 2004, as chamadas públicas de Ater e suas distintas temáticas propiciaram resultados significativos junto ao grupo de associados. A propósito, a ADESSU está participando de uma proposta, como executora, pelo fato de ser uma referência no trabalho com agricultura de base agroecológica. Na visão do mesmo entrevistado FCAD3, com o apoio das políticas públicas, mudou a forma de atuação dos técnicos extensionistas locais, pois o foco maior do trabalho passou a ser a Agroecologia. Com isso, sentiu-se a necessidade de aprofundar a discussão teórica, com uma maior abrangência para os casos práticos no campo, a fim de exemplificar a transição agroecológica, para um melhor entendimento das dimensões desse processo.

\section{Extensão rural universitária e a introdução do método camponês para minimizar a ausência dos serviços de ATER no assentamento Chico Mendes III}

No município de São Lourenço da Mata, as ações de Ater para iniciar a transição agroecológica do Assentamento Chico Mendes III ocorreram por meio de reuniões e palestras, para que os assentados tomassem conhecimento sobre os princípios da Agroecologia. Aconteceram, simultaneamente, capacitações com os professores da UFRPE, agricultores de outras localidades e técnicos de algumas ONGs. Nessa fase inicial, relembra o entrevistado FCCM2, foram realizados seguidos intercâmbios com outros produtores envolvidos com a agricultura sustentável, na expectativa de que os assentados pudessem se aproximar de estratégias e experiências de desenvolvimento rural sustentável baseadas na Agroecologia.

Nessa perspectiva, o conceito de Desenvolvimento rural sustentável, gerado a partir da Agroecologia, baseia-se no descobrimento, sistematização, análise e 
potencialização dos elementos de resistência locais das comunidades rurais ao processo de modernização homogeneizador da agricultura, para, através deles, desenhar, de forma participativa, esquemas de desenvolvimento definidos a partir da sua própria identidade local e seu ecossistema. Para isso, os planos de desenvolvimento rural sustentável devem considerar os seguintes elementos em sua elaboração: integralização entre agricultura, pecuária e silvicultura para um melhor aproveitamento dos recursos existentes; harmonia e equilíbrio entre o crescimento econômico e a qualidade do meio ambiente; autonomia de gestão e controle para os habitantes locais; redução das externalidades negativas nas atividades produtivas; criação, manutenção e fortalecimento dos circuitos curtos de produção; utilização do conhecimento local vinculado aos sistemas tradicionais de manejo dos recursos naturais; e pluriatividade, seletividade e complementariedade de rendas (GUZMÁN CASADO; GONZÁLES DE MOLINA; SEVILLA GUZMÁN, 2000).

Boa parte dessas ações eram planejadas em conjunto com os próprios agricultores. A primeira atividade realizada no assentamento foi uma caminhada coletiva que contou com a participação de professores da UFRPE e de agricultores, para conhecerem o espaço físico do assentamento. A assessoria estava basicamente relacionada a questões teóricas ou práticas ligadas à produção agroecológica e era realizada pelos professores da universidade, pelos estudantes estagiários ou técnicos envolvidos nos projetos de pesquisa e extensão ou, ainda, por outros convidados externos (técnicos de alguma organização ou agricultores de outras experiências com agricultura sustentável). Toda semana ocorria uma reunião com os agricultores que estavam envolvidos diretamente na transição, para que fossem levantados e discutidos os temas que seriam trabalhados nas atividades de produção. Essas atividades eram realizadas com a presença de um técnico que ficava responsável pela orientação dos trabalhos de campo (FCCM2).

$\mathrm{O}$ assentado ACM7 relata que, antes da transição, a produção da maioria dos assentados era basicamente de milho e de mandioca e, em alguns casos, não havia nada produzido, estando muitas áreas tomadas pelo mato. Nas reuniões, colocou-se a necessidade de recuperar os mananciais e as nascentes de água e de extinguir as queimadas; em seguida, a universidade realizou análises do solo e da água. Os técnicos que visitaram o local apresentaram algumas técnicas para os agricultores, como a adubação verde feita com plantas nativas ou adubadeiras para a recuperação do solo, o que não era do conhecimento de muitos. 
Para o preparo do solo, a UFRPE conseguiu um trator para gradear a terra, além de disponibilizar esterco, sementes e mudas de fruteiras para incentivar a produção. Depois, para auxiliar de forma mais contundente e dar um maior suporte à transição agroecológica do assentamento, foram criadas as unidades de experimentação agroecológica (UEAs), chamadas também de roçado de estudo, onde os agricultores puderam se apropriar dos novos conhecimentos socializados. A forma encontrada para minimizar a ausência dos serviços de Ater governamentais ou prestados por ONGs foi a introdução do método Camponês a Camponês (CAC), mais precisamente por meio da formação dos agricultores multiplicadores, que desempenharam um papel fundamental em todas as etapas iniciais da transição.

Sobre os serviços de Ater realizados ultimamente no assentamento Chico Mendes III, o informante FCCM1 avalia que pouca coisa mudou, haja vista que nenhuma inciativa vinculada ao MDA, ao governo estadual ou a ONGs está presente na experiência. Isso se confirma nas palavras transcritas e referidas abaixo:

Trabalhei em 2013 e não vi nenhum papel do Estado, nenhum serviço de Ater. Eu vi o carro do IPA lá umas vezes, mas eram coisas pontuais, parceria com a universidade. Foram no máximo duas ou três vezes durante o ano todo. Eu via também a Agência de Defesa e Fiscalização Agropecuária de Pernambuco (Adagro) para vacinação, mas era só isso. $\mathrm{O}$ que eu posso garantir é que às vezes a gente até tinha dificuldade de visitar todos, mas era só a universidade e os estudantes. Os agricultores também, muitas vezes, o responsável dentro da metodologia Camponês a Camponês, o responsável dava assistência com a gente, com os estagiários. Mas Ater formal do estado ou de ONG, nada (FCCM4).

Como descrito pelos informantes, a UFRPE permanece sendo a única instituição a prestar assessoria às famílias do assentamento, o que, ainda assim, não é suficiente. Entre as ações mais recentes, destaca-se a criação de feiras agroecológicas para que os agricultores possam comercializar os seus produtos em circuitos curtos, promovendo uma interação mais direta com os consumidores e barateando, assim, a logística de transporte. A universidade conseguiu montar as feiras com a aquisição de barracas padronizadas, firmando parceria com prefeituras locais para a liberação de áreas para as feiras e sua divulgação por programas de rádio.

A realização dos intercâmbios agroecológicos com agricultores de outras localidades continua, agora com menos frequência. Em compensação, constantemente, estão sendo disponibilizadas sementes produzidas em sistemas agrícolas de base 
ecológica para os assentados e também é feito um trabalho especial para a criação de bancos comunitários de sementes. Nos projetos de extensão mais atuais, vem sendo dada uma maior atenção à formação de farmácias vivas e à manipulação de plantas medicinais. Os estudantes do curso de Economia Doméstica têm focado na questão da alimentação, e o projeto intitulado "Plantar, colher, comer" visa justamente estimular o preparo de alimentos para as famílias a partir do que é produzido dentro do assentamento.

O entrevistado FCCM2 diz que todos os agricultores que participam da transição são contemplados pelas ações da UFRPE, e aquelas famílias que ainda não estão inseridas nos projetos podem se incluir a qualquer momento, desde que desenvolvam as atividades estabelecidas previamente nas reuniões. Ele evidencia ainda uma participação uniforme entre homens e mulheres, tanto nas reuniões como na execução das tarefas. Nas reuniões, "tomou-se o cuidado em ouvir as demandas deles, e a partir daí, procuramos trabalhar temas envolvendo a diversidade cultural e produtiva, uso racional dos recursos, diminuição de insumos, extinção do uso de agrotóxicos e outras coisas" (FCCM2).

Mesmo admitindo a importância da UFRPE no que diz respeito aos serviços de Ater prestados, alguns entrevistados alegam que, atualmente, as visitas dos técnicos ou estagiários não ocorrem com tanta regularidade, como foi no início da experiência. Do ponto de vista da assentada ACM1, isso vem acontecendo porque a universidade tem priorizado aqueles agricultores familiares que estão cultivando hortaliças e enviando seus produtos para as feiras. A assentada ACM2 igualmente vem sentindo esse afastamento da UFRPE no presente momento, revelando, até, que procurou o IPA, quando enfrentou problemas de ataque de "pragas" na sua área:

Os alunos da UFRPE vêm visitar, mas a assistência é esporádica. Fazem alguns trabalhos com alguns grupos pra controle de "pragas", mas não chega a todo mundo. Na minha área aqui não chega. Tem visita, eles olham, perguntam e vão embora. Já procurei alguns amigos que trabalham com fruticultura pra tirar dúvidas. Já procurei o pessoal do IPA, fui atendida, queria saber da mosca da fruta, mais pra pegar informações, quais os tipos de controle. O IPA já veio algumas vezes, mas não tem corpo técnico pra atender o município todo. Acho que veio duas vezes esse ano (ACM2).

Buscar esse apoio junto ao IPA não é o mais comum de se acontecer; pelo contrário, quando a maioria dos agricultores sente a necessidade de encontrar alternativas para os problemas evidenciados em seus sistemas produtivos, recorre quase que 
exclusivamente à UFRPE ou à Universidade Federal de Pernambuco (UFPE), que também tem projetos direcionados ao assentamento.

Eu procurei a professora da UFPE. Ela trouxe duas alunas e pegou na internet receitas. O problema foi nas fruteiras, no pé de pitomba, mamão. Quando o mamão ia amadurecer, ficava com um ferimento, era um fungo. Aí a gente tentou resolver com calcário. A gente comprou cinco sacos. Não ficou bom o mamão, mas melhorou. A professora apresentou pra gente um remédio, que pega o esterco do boi, bota em um balde de água, coloca cinza, leite, sabão, mexe, deixa por três dias, depois coa, coloca na bomba e vai (ACM3).

O fato é que os agricultores do assentamento Chico Mendes III se identificam com o trabalho dessas instituições de ensino que atuam no cotidiano das famílias. Provavelmente, a maneira como a Agroecologia foi trabalhada por esses atores contribuiu para a consolidação dessa relação costurada nos últimos anos. Os conceitos e princípios da Agroecologia estiveram presentes de forma aplicada e prática, sendo trabalhados na base da comunicação horizontal e com a ajuda daqueles agricultores que tinham mais experiência na agricultura, para que eles pudessem incentivar o restante do grupo. Com a criação de circuitos curtos de comercialização, buscou-se uma aproximação entre os agricultores e os consumidores finais, por meio da venda direta dos seus produtos nas feiras agroecológicas criadas. Através do diálogo, os consumidores compreenderam um pouco mais sobre a realidade de um assentamento de reforma agrária, inclusive tendo a oportunidade de visitar o Assentamento Chico Mendes III para conhecer a origem dos produtos que estão levando para suas casas, livres de agrotóxicos (FCCM4).

O entrevistado FCCM3 observa que o trabalho das instituições é bem aceito pelos agricultores, mas que ainda há muito a se evoluir, com um esforço coletivo diário, por meio de reuniões, continuidade dos projetos etc. A inserção dos técnicos é essencial para fazer com que tais projetos avancem, pois, além de estimularem a participação mais efetiva dos assentados, eles passam a entender a transição agroecológica a partir do contato direto com estratégias e experiências de desenvolvimento rural sustentável, por meio da troca de conhecimentos que iniciativas dessa natureza proporcionam aos envolvidos.

Conforme discutido na literatura especializada, as propostas de desenvolvimento rural sustentável, pautadas nos princípios da Agroecologia, devem levar em consideração, além da degradação ao meio ambiente, os níveis de pobreza rural, pois, para que as 
estratégias de desenvolvimento rural possam se tornar eficazes, é necessário que haja um elo entre as questões tecnológicas, econômicas e principalmente as sociais, para o enfrentamento da crise ambiental e da miséria rural que persistem no mundo em desenvolvimento (ALTIERI, 2009). A esse respeito, Sevilla Guzmán (2005) comenta que:

Essas novas estratégias de ação devem garantir o incremento da biodiversidade, no que se refere às formas de relação com os recursos naturais. Elas devem atender não somente à utilização dos mesmos, mas também à sua conservação, empregando, para isso, tecnologias que respeitem o meio ambiente e, além disso, permitam a abertura de espaços na administração, para garantir a participação local. Em suma, a Agroecologia como desenvolvimento rural sustentável, consiste na busca do local para, partindo daí, recriar a heterogeneidade do mundo rural por meio de formas de ação social coletivas (SEVILLA GUZMÁN, 2005, p. 131).

Sobre as dificuldades encontradas para o cumprimento dos serviços de Ater, o principal entrave para os técnicos ou estagiários dos projetos das universidades se refere ao receio, por parte de alguns agricultores, em passar para um modelo de agricultura sustentável, sobretudo para aqueles que "têm uma cultura mais enraizada na tradição da cana, que tinham resistência às mudanças" (FCCM4). "A dificuldade era convencer os agricultores do benefício que teriam ao trocar práticas que se tornaram mais tradicionais por outras mais sustentáveis" (FCCM2). "Por desconhecimento, algumas pessoas ainda não abraçaram a causa. A universidade tem que ter muita paciência com essas pessoas. Elas têm que entender o que é a Agroecologia. Os assentados têm que ter mais força de vontade" (ACM5).

O fonte-chave FCCM3 explana que, por a assessoria ser prestada dentro de projetos de pesquisa ou extensão universitária, quer dizer, no campo acadêmico, a extensão rural não tem como ser tão incisiva no caso do assentamento. Ele averiguou, além disso, que as mudanças ocorrem de forma gradual, justamente por não se tratar de um programa de Ater oficial voltado para os agricultores familiares e oferecido pelo Estado. A adesão dos agricultores foi outra preocupação presente em seu discurso:

A gente busca deles o que pode ser mudado, o que eles entendem que é importante. É uma coisa gradativa, e na prática. Vamos fazendo e vendo o que dá certo ou errado para ajudar. Mas, não é um programa de Ater. Quando os agricultores receberam as informações nas reuniões no assentamento, muitos se mostraram interessados, mas outros não. É aberto a todos, mas só aderiram os que realmente queriam e podiam, já 
que muitos têm problemas de saúde e não poderiam estar sempre na lida no campo. Os interessados são contemplados com esse projeto (FCCM3).

A agricultora ACM2 argumenta que, como até agora a área do assentamento não foi parcelada, as casas para as famílias ainda não foram construídas, mesmo com a emissão de posse dada há mais de quatro anos. Essa agricultora também defende que o atraso na divisão das parcelas e na construção das casas gerou outras implicações negativas, como a falta de energia elétrica por um longo período, que só passou a ser fornecida em janeiro de 2014, e a indisponibilidade do crédito para os assentados, que não permite a realização de qualquer tipo de investimento em suas UPAs. Ela detalha a sua situação vivenciada:

O grande entrave é a questão financeira para investimento. Como ainda não tem a área parcelada, o mapa de parcelamento não existe e as construções das casas não foram feitas. A gente já tem quatro anos de emissão de posse e ainda nem casa foi construída, tanto que a energia chegou somente em janeiro e aí a gente não pode pegar nenhum investimento do Banco do Nordeste. Então, fica muito difícil investir na terra, porque tem hora que a gente precisa de um trator, é 70, 80, 100 reais a hora, e uma hora só não resolve. Pra você ter uma ideia, eu estou há três meses pagando um açude que eu fiz ali embaixo, que me custou dois mil reais. Eu não tenho salário fixo, só recebo 800 reais por mês das consultorias que eu faço. Então, eu estou pagando parcelado. Também tem o sistema de irrigação, é muito cano pra colocar, eu não entendo bem como funciona, e pra pagar uma pessoa pra fazer não dá, porque queriam me cobrar 400 reais e eu não tenho 400 reais. Daí eu saí desenhando, pesquisando, e meu pai disse que essa semana a gente ia cavar e colocar os canos. Tudo é muito caro pra poder produzir, semente, carro pra comercializar, caixa pra botar a mercadoria (ACM2).

Além da falta do crédito rural para investir em suas unidades produtivas, o assentado ACM4 menciona alguns problemas de cunho mais prático sentidos no campo, como a dificuldade para roçar o mato e para realizar o plantio no sistema de leiras. Ele complementa falando das feiras agroecológicas, que, na sua visão, apesar de estarem ajudando na renda das famílias participantes, precisam de um reforço. A feira realizada em Recife, a qual proporciona um melhor retorno financeiro aos agricultores, com a venda dos seus produtos, antes contava com cinco barracas, mas, com a falta de comprometimento de alguns, passou a ter quatro barracas (ACM4). Nessa situação específica, fica evidenciada tanto a falta de articulação e associativismo entre os assentados, para a organização e divisão dos custos com o transporte para levar os 
produtos à feira, como também a dependência dos agricultores no apoio da universidade, já que eles esperam que a instituição ofereça esse transporte, cedendo seus automóveis, o que não pode ser feito de maneira alguma.

Sobre a influência das políticas públicas no caso do assentamento Chico Mendes III, a análise mostra que isso é inexistente. Diferente do que acontece com alguns agricultores de Santa Cruz da Baixa Verde, nenhuma instituição estatal de Ater tem atuação permanente junto aos assentados. O máximo que se pode dizer é que os mesmos programas governamentais para compra de alimentos (PAA e PNAE) que impulsionam a experiência da ADESSU, quando divulgados, causaram certo entusiasmo com a possibilidade de os agricultores venderem os seus produtos a um preço mais justo, porém o que houve até aqui foi somente a proposta para inseri-los nesses programas.

\section{Considerações finais}

Desde a criação da PNATER em 2004, observa-se que as políticas de extensão rural subsequentes apresentam ambiguidades, distorções e fragilidades, tanto de ordem teórica quanto metodológica, ainda assim, não se pode desconsiderar o estímulo à incorporação da Agroecologia às dinâmicas de desenvolvimento rural, considerando as diferentes situações socioeconômicas, produtivas, ambientais e de organização associativa presentes nas estratégias e experiências dos agricultores familiares.

O fato é que, paralelamente às políticas preconizadas pela esfera governamental, nos últimos anos, no Brasil, cada vez mais agricultores familiares vêm desenvolvendo estratégias e experiências de desenvolvimento rural pautadas nos princípios da Agroecologia. Muitas dessas estratégias e experiências, como nos dois casos apreciados, recebem o apoio de associações e cooperativas agrícolas; sindicatos rurais; ONGs que trabalham na promoção da agricultura familiar e do desenvolvimento rural sustentável; organizações governamentais; institutos de pesquisa que atuam no âmbito das Ciências Agrárias; universidades e seus projetos de pesquisa e extensão; órgãos de fomento à pesquisa científica e tecnológica; entre outros atores. Além disso, é possível reconhecer que existe também o incentivo advindo de outras políticas públicas voltadas aos agricultores familiares, como é o caso da linha especial do Programa Nacional de Fortalecimento da Agricultura Familiar (Pronaf), o Pronaf Agroecologia, orientado para o financiamento de projetos de investimento de sistemas de produção agroecológicos ou orgânicos. 
Constata-se em Santa Cruz da Baixa Verde que as forças mobilizadas em torno da ação estratégica de desenvolvimento rural sustentável eram fundamentalmente locais e suas motivações extrapolavam as de ordem estritamente econômica. O enraizamento dessas forças aparentemente se transfere com êxito para o arranjo produtivo, fazendo com que hoje os agricultores familiares da ADESSU identifiquem suas perspectivas de futuro com as do processo de transição agroecológica e da prática da agricultura sustentável.

No caso do assentamento Chico Mendes III, as condições que permitiram o surgimento do processo de transição agroecológica têm menos a ver com fatores endógenos à história do município e das famílias, e mais com oportunidades geradas pelo apoio da UFRPE - a decisão de criar um projeto voltado à transição agroecológica partiu da universidade em um contexto de importantes transformações das políticas públicas da extensão rural no país. Até a criação oficial do projeto de apoio à transição agroecológica, o assentamento não possuía iniciativas dessa natureza. Sendo assim, o elemento propriamente mobilizador não tem raízes locais; ao contrário, as iniciativas vieram praticamente todas de fora.

\section{Referências bibliográficas}

ALTIERI, M. Agroecologia: a dinâmica produtiva da agricultura sustentável. 5. ed. Porto Alegre: Editora da UFRGS, 2009.

BRASIL. Política Nacional de Assistência Técnica e Extensão Rural. Brasília: MDA/SAF/DATER-IICA, 2004.

BRASIL. Lei $\mathrm{N}^{\circ}$ 11. 326, de 24 de julho de 2006. Estabelece as diretrizes para a formulação da Política Nacional de Agricultura Familiar e Empreendimentos Familiares Rurais. Diário Oficial [da] República Federativa do Brasil, Poder Executivo, Brasília, DF, 2006. Disponível em: <http://www.planalto.gov.br/ccivi 103/Ato2004-2006/2006/Lei/L11326. htm>. Acesso em: 10 jan. 2016.

BRASIL. Decreto No 6.323, de 27 de dezembro de 2007. Regulamenta a Lei no 10.831, de 23 de dezembro de 2003, que dispõe sobre a agricultura orgânica, e dá outras providências. Diário Oficial [da] República Federativa do Brasil, Poder Executivo, Brasília, DF, 2007. Disponível em: <http://www.planalto.gov.b r/ccivil_03/_ato2007-2010/2007/Decreto/D6323 .htm>. Acesso em: 26 jan. 2016.

BRASIL. Lei de Ater $N^{\circ}$ 12.188/2010. Institui a Política Nacional de Assistência Técnica e Extensão Rural para a Agricultura Familiar e Reforma Agrária - PNATER e o Programa Nacional de Assistência Técnica e Extensão Rural e na Reforma Agrária - PRONATER. Diário Oficial [da] República Federativa do Brasil, Poder Executivo, Brasília, DF, 2010. Disponível em: <http://www.mda.gov.br/portal/instituc ional/novaleideater> Acesso em: 10 jan. 2016. 
BRASIL. $1^{\text {a }}$ Conferência Nacional sobre Assistência Técnica e Extensão Rural. Ater para a agricultura familiar e reforma agrária e o desenvolvimento sustentável do Brasil rural. Documento-base. Brasília: MDA/SAF/DATER, 2012.

BRASIL. Decreto No 7.794, de 20 de agosto de 2012. Institui a Política Nacional de Agroecologia e Produção Orgânica. Diário Oficial [da] República Federativa do Brasil, Poder Executivo, Brasília, DF, 2012. Disponível em: < http://www.planalto.gov. br/ccivil_03/_ato20112014/2012/decreto/d7794.htm>. Acesso em: 26 jan. 2016.

CAPORAL, F. R.; COSTABEBER, J. A. Agroecologia e Extensão Rural: contribuições para a promoção do desenvolvimento rural sustentável. Brasília: MDA/SAF/DATER, 2007.

CAPORAL, F. R. Em defesa de um Plano Nacional de Transição Agroecológica: compromisso com as atuais e nosso legado para as futuras gerações. In: SAUER, S.; BALESTRO, M. V. (Org.). Agroecologia e os desafios da transição agroecológica. São Paulo: Expressão popular, 2009.

CAPORAL, F. R. Lei de Ater: exclusão da Agroecologia e outras armadilhas. Revista de Agroecologia e Desenvolvimento Rural Sustentável, v.4, n.1, p. 23-33, 2011.

COSTABEBER, J. A. Acción colectiva y procesos de transición agroecológica en Rio Grande do Sul, Brasil. Tesis (Doctorado en Agroecología, Campesinado e Historia). Instituto de Sociología y Estudios Campesinos. Universidad de Córdoba (España), 1998.

GUZMÁN CASADO, G. I.; GONZÁLEZ DE MOLINA, M.; SEVILLA GUZMÁN, E. Introducción a la Agroecología como desarrollo rural sostenible. Ediciones Mundi-Prensa: Madrid; Barcelona; México. 2000.

ROJAS SORIANO, R. Manual de pesquisa social. Petrópolis, RJ: Vozes, 2004.

SEVILLA GUZMÁN, E. Agroecologia e desenvolvimento rural sustentável. In: AQUINO, A. M.; ASSIS, R. L. (Eds.) Agroecologia: princípios e técnicas para uma agricultura orgânica sustentável. Brasília, DF: Embrapa Informação Tecnológica, 2005. 